\title{
Rachel Grace Newman (2014), Los niños migrantes entre Michoacán y California. Pertenencia, Estado-nación y educación, 1976-1987, El Colegio de Jalisco, Zapopan
}

\author{
Laura Echavarría Canto ${ }^{1}$ \\ Departamento de Investigaciones Educativas, Cinvestav \\ lechavar@cinvestav.mx
}

En este interesante libro la autora investiga las dimensiones de pertenencia de los niños migrantes de Gómez Farías, Michoacán, que pasaban largas estancias en Watsonville, California, como hijos de jornaleros agrícolas y que estudiaron una parte del ciclo escolar en Estados Unidos y otra parte en México, durante el periodo 1976 a 1987, para dar cuenta del hecho de que aunque ambos estados-nación intentaron que estos niños encajaran en una formulación tradicional de pertenencia, el hecho de que sus identidades estuvieran conformadas por prácticas y experiencias de tránsito, imposibles de contener dentro de un solo Estado-nación territorial, dio lugar a su adscripción a pertenencias cruzadas, plurales o divididas, es decir, a pertenencias trasnacionales.

Grace Newman construye la noción de pertenencia trasnacional a partir del análisis de tres vetas de la identidad: a) los vínculos territoriales, en los que destaca el concepto de idiótopo (Pascual-de-Sans), en tanto lugar ideal escogido por los individuos, y el hecho de que si bien los entrevistados poseen idiotópos el tenerlos no les ha facilitado la vida trasnacional porque la pluralidad de lugares que llegaron a conocer creó un entramado de vínculos territoriales complejos donde la pertenencia es incompatible con el estilo de vida o donde el estilo de vida impide formar un sentido de pertenencia; ) la pertenencia cultural-nacional, donde sobresale que las narrativas de la identidad cultural que rescata de las entrevistas

${ }^{1}$ Adscrita al área de Análisis Político de Discurso e Investigación en el Departamento de Investigaciones Educativas del Cinvestav-IPN. Doctora en Pedagogía (2014) por la Universidad Nacional Autónoma de México. Maestra en Pedagogía (2007) y Licenciada en Economía (2000) por esa misma institución. Especialización en análisis de Políticas Educativas (UIA) y Especialización en Economía Laboral (UNAM). 
indican que la vida trasnacional y la niñez trasnacional no necesariamente impiden la formación de pertenencias nacionales o regionales; y c) la ciudadanía, en la que señala que los migrantes entrevistados no han ejercido plenamente su ciudadanía mexicana y tampoco tienen la estadounidense.

A nivel teórico la autora debate con los estudios tradicionales de migración, ya que han planteado un "armazón bipolar" para describir la experiencia migrante, admitiendo sólo dos posibilidades: la circular y la lineal. Para ella estos modelos no reconocen la posibilidad de procesos migratorios que no conducen ni a la asimilación ni al retorno permanente, ni las formaciones identitarias complejas o plurales que un migrante puede desarrollar. Asimismo, aborda perspectivas teóricas que aceptan que la realidad empírica no coincide con los modelos lineal y circular y que en la búsqueda de un modelo más flexible y adecuado a la realidad compleja que observaban plantearon el concepto de trasnacionalismo que, de acuerdo con la definición de Glick, Basch y Szanton, pioneras de este modelo, alude a que los migrantes trasnacionales son las personas "cuyas vidas cotidianas dependen de interconexiones múltiples y constantes a través de las fronteras internacionales y cuyas identidades públicas se configuran en relaciones con más de un Estado-nación”.

Desde esta perspectiva, la autora retoma críticamente dos nociones teóricas que le permiten acotar su investigación. La primera es el circuito migratorio, que hace hincapié en el modo en que las actividades económicas, sociales y culturales que los migrantes llevan a cabo en diferentes lugares permiten formar una sola comunidad trasnacional, de la cual la autora se distancia al considerar que sugiere un movimiento predeterminado, cuando en realidad los movimientos migratorios pueden variar en el tiempo, y porque considera que minimiza la experiencia migratoria en los distintos sitios que constituyen el circuito, lo cual sesga el análisis de las prácticas trasnacionales al enmarcarlas dentro de un esquema mecanicista y homogeneizador. Por ello es que aborda la segunda noción, la categoría de campo social trasnacional, desarrollada por Levitt y Glick, la cual argumenta que las redes de los migrantes conformaron un solo campo social localizado en diferentes sitios, lo que desde el punto de vista de la autora pone el acento en la heterogeneidad y la multidimensionalidad de la espacialidad migrante, pero da poca importancia al territorio y deja de lado la dimensión espacial de la migración trasnacional. Newman no descarta estas nociones, pero su interés se encuentra en proponer otra perspectiva a la espacialidad de los migrantes trasnacionales, una espacialidad que reconozca la agencia de los actores sociales para construir el espacio y la simultaneidad de las prácticas y vivencias trasnacionales, a la cual llama la región trasnacional. Región trasnacional que construye, a partir de la presentación de la particularidad histórica, geográfica y demográfica de Gómez Farías y de Watsonville, como un acercamiento inicial para poder mostrar que la espacialidad de las familias migrantes de Gómez Farías 
traza una región trasnacional caracterizada por lazos sociales, culturales y económicos transfronterizos.

La región trasnacional dará estructura a toda la investigación y con ella se refiere a la región definida por procesos sociales trasnacionales que se asientan en un territorio discontinuo. Esta categoría construida ex profeso para su investigación le permite abordar una de sus principales preguntas de investigación: ¿a qué territorio, nación y Estado pertenecían y pertenecen los niños migrantes? Partiendo de dos tipos de pertenencia, la pertenencia desde arriba, que es aquella diseñada por los Estados mexicano y estadounidense en torno a la pertenencia nacional y la ciudadanía de estos niños y la pertenencia desde abajo, aquella asociada a la agencia de los actores que expresan su propia pertenencia.

Esta perspectiva responde también a otras dos de las preguntas de investigación: ¿qué tipo de pertenencia puede formar una persona que creció y se educó en un ámbito trasnacional? ¿Qué hacen los estados cuando los hijos de sus ciudadanos no residen en el territorio nacional de manera permanente? Ambas preguntas son uno de los ejes del libro, pues al investigar estas problemáticas, en el caso de los niños migrantes y de los proyectos educativos diseñados para darles continuidad escolar a través de un proyecto binacional que inició en 1976, la autora da cuenta de la dificultad de proponer, implementar e institucionalizar programas diseñados para actores trasnacionales que se mueven entre dos estados-nación.

En este contexto, una parte importante del libro está dedicada a dar cuenta de la historia de Arlene Dorn, promotora principal de estos proyectos educativos y quien fuera una maestra estadounidense que promovió el intercambio de información escolar sobre los niños migrantes entre los sistemas educativos de México y Estados Unidos. Este proyecto, Ilamado "Gómez Farías" y posteriormente Migrant Education Data International Record (MEDIR), se institucionalizó en 1987 como el Programa Binacional de Educación Migrante (Probem), que actualmente tiene validez oficial en ambos lados de la frontera. Newman considera que Dorn fue el motor principal de estos proyectos, junto con su contraparte mexicana, Irene Anzaldúa, cuyos esfuerzos no han recibido el reconocimiento que merecen, algo que este libro pretende subsanar.

Un aporte valioso de este texto es la estrategia metodológica utilizada en la investigación, es decir, la metodología histórico-etnográfica, que se centró en identificar, clasificar e interpretar los discursos de pertenencia a partir de gran variedad de fuentes primarias que respondieran a la pregunta de ¿quiénes eran y a dónde pertenecían los niños migrantes? Para ello, Newman estudió las respuestas de tres grupos de voces: el Estado mexicano, el estadounidense y los niños migrantes (cuatro de ellos a quienes entrevista siendo ya adultos en enero de 2011) con la intención de desenmascarar versiones manipuladas del pasado y resaltar las historias que se han ocultado u olvidado, es decir, hacer historia desde abajo. Sin embargo, desde una perspectiva decolonial habría que cuestionar el hecho de que la meto- 
dología propuesta, al querer dar voz a lo silenciado, al mismo tiempo lo estaría negando, ya que la autora lo piensa a partir de marcos analíticos occidentales reglamentados desde los centros hegemónicos del saber.

Por último, las conclusiones muestran tres hallazgos principales. El primero es el hecho de que ambos Estados-nación concibieron a los niños migrantes partiendo del supuesto de que las prácticas trasnacionales de sus familias eran temporales, perdiendo de vista que el trasnacionalismo perduró porque estos niños migrantes se convirtieron en adultos trasnacionales. El segundo son los modos de vida trasnacionales pueden dar lugar a la formación de pertenencias múltiples y complejas que pueden ser nacionales y trasnacionales de manera simultánea. El tercer hallazgo es que existe una profunda incompatibilidad entre los modelos de pertenencia promovidos desde arriba y las pertenencias experimentadas y narradas por los actores trasnacionales. 